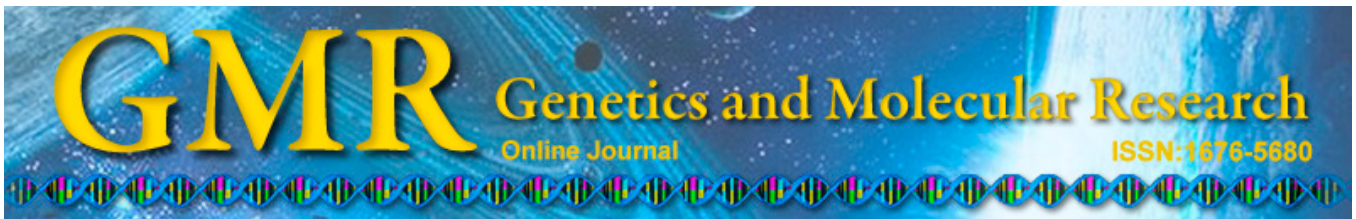

\title{
Assessment of sensitivity and virulence fitness costs of the AvrPik alleles from Magnaporthe oryzae to isoprothiolane
}

\author{
W.H. Wu ${ }^{1,2}$, L. Wang ${ }^{2}$, S. Zhang ${ }^{2}$, Y.Q. Liang ${ }^{1}$, X.L. Zheng ${ }^{1}$, K.X. Yi ${ }^{1}$ and \\ C.P. $\mathrm{He}^{1}$ \\ ${ }^{1}$ Hainan Key Laboratory for Monitoring and Control of Tropical Agricultural \\ Pests, Environment and Plant Protection Institute, \\ Chinese Academy of Tropical Agricultural Sciences, Haikou, Hainan, China \\ ${ }^{2}$ Guangdong Provincial Key Laboratory for Microbe Signals and Crop \\ Disease Control, South China Agricultural University, Guangzhou, China \\ Corresponding authors: C.P. He / K.X. Yi \\ E-mail: hechunppp@163.com / yikexian@126.com
}

Genet. Mol. Res. 13 (4): 9701-9709 (2014)

Received January 21, 2014

Accepted June 30, 2014

Published November 24, 2014

DOI http://dx.doi.org/10.4238/2014.November.24.1

\begin{abstract}
The in vitro sensitivity of AvrPik allele isolates of Magnaporthe oryzae to isoprothiolane was examined and the virulence fitness costs of AvrPik allele isolates to isoprothiolane were assessed. Isoprothiolane was found to suppress the radial growth of AvrPik allele isolates at all concentrations $(1,5,10,15$, and $20 \mu \mathrm{g} / \mathrm{mL})$. Generally, a higher isoprothiolane concentration has a stronger inhibitory effect on mycelial growth in AvrPik allele isolates at 6 and 10 days after inoculation. The inhibitory effect of isoprothiolane also increased with treatment time. To determine whether a correlation existed between the in vitro sensitivity of AvrPik allele isolates and virulence, the halfmaximal inhibitor concentration and $75 \%$ of the maximum inhibitor concentration were calculated for each mutation isolate and wild-type isolate. Based on these values and virulence, no significant correlation between the susceptibility of AvrPik allele isolates and virulence was
\end{abstract}


detected. In summary, no fitness costs were associated with sensitivity of blast isolates carrying specific AvrPik alleles to different virulence.

Key words: AvrPik alleles; Fitness costs; Isoprothiolane; Magnaporthe oryzae

\section{INTRODUCTION}

Rice blast disease caused by the filamentous ascomycete fungus Magnaporthe oryzae is one of the most devastating diseases of rice worldwide (Talbot, 2003; Liu et al., 2010). The disease causes heavy yield losses, ranging from $35-50 \%$ during the epidemic years (Padmavathi et al., 2005). The use of resistant varieties is the most economical and effective method of controlling rice blast mainly in resource-poor fields (Séré et al., 2007). To date, more than 80 resistance genes related to rice blast disease have been reported, and some have been used to control the disease (Ballini et al., 2008). For example, in the southern United States, Pitabased resistant cultivars including Katy, Drew, Kaybonnet, Madison, Cybonnet, Ahrent, and Banks have been widely utilized to control blast disease since the release of the first Pitacontaining cultivar, Katy, in 1990 (Moldenhauer et al., 1990; Jia et al., 2004). Although $R$ gene-mediated resistance is highly effective once it is triggered, breeding of resistant cultivars often shows only short-term success, which is mainly because of the frequent appearance of new races (or pathotypes) of the fungus that are virulent to previously resistant cultivars (Lee et al., 2005). New virulent races of the pathogen may have emerged by genetic modification of avirulence ( $A v r)$ genes through several mechanisms, including deletion of the entire gene (Dai et al., 2010; Takahashi et al., 2010), nonsynonymous point mutations (Yoshida et al., 2009), frameshift mutations (Dai et al., 2010), or transposon insertions (Fudal et al., 2005; Zhou et al., 2007; Li et al., 2009). Generally, Avr genes in M. oryzae are highly diverse and are predicted to be capable of rapid changes in nature (Jia et al., 2000). Thus, the pathogenic Avr gene product is no longer 'recognized' by the host $R$ gene or can no longer modify the plant guard protein, rendering host resistance ineffective (Jones and Dangl, 2006). To date, more than 40 M. oryzae Avr genes have been genetically analyzed (Ma et al., 2006), 9 of which have been cloned: PWL1 (Kang et al., 1995), PWL2 (Sweigard, 1995), Avr1-CO39 (Farman and Leong, 1998), Avr-Pita (Orbach et al., 2000), ACE1 (Fudal et al., 2005), Avr-Pizt (Li et al., 2009), Avr-Pia, Avr-Pii, and Avr-Pik/km/kp (Yoshida et al., 2009).

The durability of an $R$ gene may be predicted from the information regarding the fitness cost of the pathogen's virulence at the corresponding locus (Leach et al., 2001). The fitness cost associated with pathogen evolution from avirulence to virulence to overcome host resistance can also affect the durability of resistance (Vera Cruz et al., 2000). A study by Huang et al. (2010) suggested that there are fitness costs of virulence at both the AvrLm1 and AvrLm4 loci in Leptosphaeria maculans, but there are also differences in fitness costs of virulence between the 2 loci. Recently, the rice blast Pik alleles, which confer high levels of resistance to blast, have been used in many rice breeding programs in China (Wang et al., 2009; Zhai et al., 2011). The resistance gene Pik corresponds to the avirulent gene AvrPik. The AvrPik coding region harbors 4 ubiquitous, non-synonymous single-nucleotide polymorphisms (C136A, C139G, G143A, and G234A) resulting in four major variations (H46N, P47A, G48D, and M78I) (Yoshida et al., 2009). The four major single-nucleotide polymorphisms at AvrPik can give rise to 16 genotypic combinations. All possible alleles were created by site-directed muta- 
genesis and then subjected to pathotype testing and identification of 5 pathotypes (Wu, 2012). However, the fitness cost of virulence at AvrPik locus has not been examined.

Chemical control is an effective method of controlling rice blast. Isoprothiolane (diisopropyl 1,3-dithilan-2-ylidene malonate), a dithiolane-related fungicide belonging to the organo sulfur group of compounds, can be used as an insecticide. It is used in the cultivation of rice plants because of its insecticidal effect on brown planthoppers (Uesugi, 2001). Isoprothiolane has been the primary chemical used for blast disease control since the early 1980s in China (Yuan et al., 2005; Qi et al., 2013). However, the sensitivity of AvrPik allele isolates of $M$. oryzae to isoprothiolane is unknown. To obtain a comprehensive understanding of the sensitivity of AvrPik allele isolates of M. oryzae to isoprothiolane, 8 of the $16 \mathrm{AvrPik}$ allele isolates with different genotypes and pathotypes were subjected to susceptibility testing. We determined that there is fitness costs associated with the evolution to virulence at the AvrPik locus in M. oryzae.

\section{MATERIAL AND METHODS}

\section{Fungal isolates and fungicides}

Two wild-type isolates of M. oryzae CHL724 and CHL346 and 8 of the 16 AvrPik allele isolates with different genotypes and pathotypes were used throughout these experiments (Table 1). The field blast isolate CHL724 carrying $\mathrm{N}_{46} \mathrm{~A}_{47} \mathrm{D}_{48} \mathrm{I}_{78}$ was virulent to all $4 P i k$ alleles (IRBLkp-K60, Pik- $p$; IRBLk-Ka, $P i k$; IRBLkm-Ts, $P i k-m$; and IRBLkh-K3, $P i k-h$; V/V/V/V) and the wild-type isolate CHL346 carrying $\mathrm{H}_{46} \mathrm{P}_{47} \mathrm{G}_{48} \mathrm{M}_{78}$ was avirulent to all 4 Pik alleles; the former was used as a recipient and the latter as a donor (wild) isolate. Among the 8 mutation isolates, KM1 was derived from the Pik allele-avirulent isolate CHL346. Additionally, the other 7 mutants derived from the 4 key single-nucleotide polymorphism site-directed mutations of the wild type were introduced into the Pik allele-virulent isolate CHL724 via Agrobacterium-mediated transformation (Table 1). Isoprothiolane $40 \mathrm{WP}$ was supplied by Zhongnong Zhushang (Tianjin) Agricultural Chemicals Co., Ltd. (Tianjin, China) and dissolved in $\mathrm{H}_{2} \mathrm{O}$ to $2 \times 10^{3} \mu \mathrm{g} / \mathrm{mL}$.

\section{Fungal growth inhibition assay}

The inoculums in all experiments were obtained from colonies grown in complete medium $(50 \mathrm{~mL} 20 \mathrm{X}$ nitrate salts, $1 \mathrm{~mL}$ trace elements, $10 \mathrm{~g}$ D-glucose, $2 \mathrm{~g}$ peptone, $1 \mathrm{~g}$ yeast extract, $1 \mathrm{~g}$ casamino acid, $1 \mathrm{~mL}$ vitamin solution, $20 \mathrm{~g}$ agar, and added $\mathrm{H}_{2} 0$ to a total volume of $1 \mathrm{~L}$; the $\mathrm{pH}$ of the complete medium was adjusted to $\mathrm{pH} 6.5$ using $1 \mathrm{~N} \mathrm{NaOH})$. A range of concentrations $(0,1,5,10,15$, and $20 \mu \mathrm{g} / \mathrm{mL})$ of a current anti-rice blast fungicide (isoprothiolane $40 \mathrm{WP}$ ) was used to detect the mycelial growth of blast isolates carrying specific AvrPik alleles. A control (without fungicide) was seeded with $5 \mathrm{~mm}$ agar plug containing blast mycelium, which was initially grown for 10 days and incubated at $28^{\circ} \mathrm{C}$. The spread of mycelium was recorded at 6 and 10 day intervals after inoculation (DAI) by measuring the diameter along the 2 perpendicular lines on the underside of the Petri dishes. The percent inhibition of blast isolates carrying specific AvrPik alleles in each treatment was recorded over the control and calculated using the following formula: Inhibition of blast isolates $(\%)=[($ colony growth in control - colony growth in treatment) / (colony growth in control)] x $100 \%$. 
The growth rate as a function of isoprothiolane concentration was estimated by polynomial regression, from which the half-maximal inhibitor concentration $\left(\mathrm{EC}_{50}\right)$ and $75 \%$ of the maximum inhibitor concentration $\left(\mathrm{EC}_{75}\right)$ values were estimated. Three independent biological replicates with 3 technical replicates per blast isolated were conducted. Data collected were subjected to statistical analysis using simple analysis of variance (SAS, 2002).

\section{RESULTS}

\section{AvrPik allele sensitivity evaluation}

To detect the sensitivity of AvrPik allele isolates, we evaluated the percent inhibition at different concentrations of isoprothiolane. The results showed that the inhibitory effect of isoprothiolane generally increased with increasing concentration with respect to mycelial growth at 6 and 10 DAI (Table 2). At 6 DAI, the inhibitory effect of isoprothiolane at 1, 5, 10 , and $15 \mu \mathrm{g} / \mathrm{mL}$ did not significantly differ among the 10 isolates, while a significant effect was observed among the 10 isolates when $20 \mu \mathrm{g} / \mathrm{mL}$ isoprothiolane was applied. Minimum inhibition was observed in KM12 (14.76\%), KM12 (33.51\%), KM4 (62.78\%), and KM16 (74.29) at $1,5,10$, and $15 \mu \mathrm{g} / \mathrm{mL}$, respectively, and the maximum was observed in KM1 (22.32\%), CHL346 (41.81\%), CHL346 (66.63\%), and CHL346 (80.68\%; Table 2). For the $20 \mu \mathrm{g} / \mathrm{mL}$ concentration, minimum inhibition (79.1\%) was observed in KM16 and maximum (88.19 and 84.74\%) in CHL346 and KM1 (Table 2). The remaining mutants showed a similar percent inhibition, ranging from 81.34-83.18\%, which was similar to the wild-type CHL724 $(81.03 \%)$. These results suggest that isoprothiolane effectively suppressed the radial growth of the AvrPik allele isolates at all concentrations, including 1, 5, 10, 15, and $20 \mu \mathrm{g} / \mathrm{mL}$ (Figure 1).

Table 1. Different AvrPik alleles with different genotypes and pathotypes tested.

\begin{tabular}{|c|c|c|c|c|c|}
\hline \multirow[t]{2}{*}{ Isolate/mutant ${ }^{\mathrm{a}}$} & \multicolumn{4}{|c|}{ Four major minor amino acids mutated ${ }^{\mathrm{b}}$} & \multirow{2}{*}{$\frac{\text { Pathotypes }^{\mathrm{c}}}{P i k p / k / k m / k h}$} \\
\hline & 46 & 47 & 48 & 78 & \\
\hline CHL724 & $\mathrm{N}$ & A & $\mathrm{D}$ & I & $\mathrm{V} / \mathrm{V} / \mathrm{V} / \mathrm{V}$ \\
\hline CHL346 & $\mathrm{H}$ & $\mathrm{P}$ & G & $\mathrm{M}$ & $\mathrm{A} / \mathrm{A} / \mathrm{A} / \mathrm{A}$ \\
\hline KM1 & $\mathrm{H}$ & $\mathrm{P}$ & $\mathrm{G}$ & $\mathrm{M}$ & $\mathrm{A} / \mathrm{A} / \mathrm{A} / \mathrm{A}$ \\
\hline KM2 & $\mathrm{N}$ & $\mathrm{P}$ & G & $\mathrm{M}$ & $\mathrm{V} / \mathrm{A} / \mathrm{A} / \mathrm{A}$ \\
\hline KM4 & $\mathrm{H}$ & $\mathrm{P}$ & $\mathrm{D}$ & $\mathrm{M}$ & $\mathrm{A} / \mathrm{A} / \mathrm{A} / \mathrm{A}$ \\
\hline KM6 & $\mathrm{N}$ & A & G & M & $\mathrm{V} / \mathrm{V} / \mathrm{A} / \mathrm{A}$ \\
\hline KM8 & $\mathrm{N}$ & $\mathrm{P}$ & G & I & $\mathrm{V} / \mathrm{V} / \mathrm{A} / \mathrm{V}$ \\
\hline KM12 & $\mathrm{N}$ & A & $\mathrm{D}$ & M & $\mathrm{V} / \mathrm{V} / \mathrm{A} / \mathrm{A}$ \\
\hline KM14 & $\mathrm{N}$ & $\mathrm{P}$ & $\mathrm{D}$ & I & $\mathrm{V} / \mathrm{V} / \mathrm{V} / \mathrm{V}$ \\
\hline KM16 & $\mathrm{N}$ & A & $\mathrm{D}$ & I & $\mathrm{V} / \mathrm{V} / \mathrm{V} / \mathrm{V}$ \\
\hline
\end{tabular}

${ }^{a}$ The Magnaporthe oryzae isolates CHL724 and CHL346 were used as recipient and donor (wild-type) isolates, respectively, and mutants were prefixed by KM. KM1-16 is a transformant derived from the target gene isolated from the donor isolate (CHL346) and introduced into the recipient isolate (CHL724), respectively. ${ }^{\text {bMutated }}$ positions are underlined. ${ }^{c}$ Monogenic lines carrying the cognate allelic $R$ genes (Pik-p, Pik, Pik-m, and $\left.P i k-h\right)$ were used for the pathotype test: $\mathrm{A}=$ avirulent; $\mathrm{V}=$ virulent.

At 10 DAI, however, the inhibitory effect of isoprothiolane at 1,5 , and $10 \mu \mathrm{g} / \mathrm{mL}$ did not differ significantly among the 10 isolates. The inhibitory effect differed significantly at 15 and $20 \mu \mathrm{g} / \mathrm{mL}$. The minimum inhibition was observed in KM16 (11.24\%), KM12 (27.51\%), and $\mathrm{KM} 8(56.05 \%)$ at 1,5 , and $10 \mu \mathrm{g} / \mathrm{mL}$, respectively, and maximum in $\mathrm{KM} 6(16.15 \%)$, CHL346 (35.07\%), and CHL346 (61.78\%), respectively (Table 3). At $15 \mu \mathrm{g} / \mathrm{mL}$, minimum inhibition (68.91\%) was observed in CHL724 and the maximum (77.77\%) in CHL346 (Table 3). 
At $20 \mu \mathrm{g} / \mathrm{mL}$, minimum inhibition (77.34\%) was observed in KM14 and maximum (85.63\%) in CHL346 (Table 3). This suggests that the inhibitory effect of isoprothiolane at all 5 concentrations at $10 \mathrm{DAI}$ were better than those at $6 \mathrm{DAI}$, so treatment time affects the inhibitory effect of isoprothiolane. These results indicate that isoprothiolane inhibits mycelial growth of blast isolates carrying specific AvrPik alleles in vitro at all 5 concentrations used, particularly at high concentration. AvrPik alleles isolates were sensitive to isoprothiolane.

Table 2. Effect of varying concentrations of isoprothiolane on mycelial growth of blast isolates carrying specific AvrPik alleles in vitro at 6 days after inoculation.

\begin{tabular}{|c|c|c|c|c|c|}
\hline \multirow[t]{2}{*}{ Isolate/mutant } & \multicolumn{5}{|c|}{ Percent inhibition at different concentrations of isoprothiolane } \\
\hline & $1 \mu \mathrm{g} / \mathrm{mL}$ & $5 \mu \mathrm{g} / \mathrm{mL}$ & $10 \mu \mathrm{g} / \mathrm{mL}$ & $15 \mu \mathrm{g} / \mathrm{mL}$ & $20 \mu \mathrm{g} / \mathrm{mL}$ \\
\hline CHL724 & $17.47^{\mathrm{A}}$ & $37.44^{\mathrm{A}}$ & $64.98^{\mathrm{A}}$ & $76.67^{\mathrm{A}}$ & $81.03^{\mathrm{BC}}$ \\
\hline CHL346 & $16.38^{\mathrm{A}}$ & $41.81^{\mathrm{A}}$ & $66.63^{\mathrm{A}}$ & $80.68^{\mathrm{A}}$ & $88.19^{\mathrm{A}}$ \\
\hline KM1 & $22.32^{\mathrm{A}}$ & $39.69^{\mathrm{A}}$ & $65.07^{\mathrm{A}}$ & $75.74^{\mathrm{A}}$ & $84.74^{\mathrm{A}}$ \\
\hline KM2 & $19.35^{\mathrm{A}}$ & $37.65^{\mathrm{A}}$ & $63.56^{\mathrm{A}}$ & $76.66^{\mathrm{A}}$ & $81.42^{\mathrm{BC}}$ \\
\hline KM4 & $15.84^{\mathrm{A}}$ & $34.19^{\mathrm{A}}$ & $62.78^{\mathrm{A}}$ & $76.00^{\mathrm{A}}$ & $81.34^{\mathrm{BC}}$ \\
\hline KM6 & $18.50^{\mathrm{A}}$ & $40.73^{\mathrm{A}}$ & $64.70^{\mathrm{A}}$ & $75.80^{\mathrm{A}}$ & $83.18^{\mathrm{BC}}$ \\
\hline KM8 & $20.72^{\mathrm{A}}$ & $35.54^{\mathrm{A}}$ & $65.53^{\mathrm{A}}$ & $76.24^{\mathrm{A}}$ & $81.75^{\mathrm{BC}}$ \\
\hline KM12 & $14.76^{\mathrm{A}}$ & $33.51^{\mathrm{A}}$ & $65.15^{\mathrm{A}}$ & $74.37^{\mathrm{A}}$ & $81.85^{\mathrm{BC}}$ \\
\hline KM14 & $18.00^{\mathrm{A}}$ & $38.54^{\mathrm{A}}$ & $63.69^{\mathrm{A}}$ & $74.93^{\mathrm{A}}$ & $79.96^{\mathrm{BC}}$ \\
\hline KM16 & $16.85^{\mathrm{A}}$ & $41.11^{\mathrm{A}}$ & $64.30^{\mathrm{A}}$ & $74.29^{\mathrm{A}}$ & $79.10^{\mathrm{C}}$ \\
\hline
\end{tabular}

Means with the same letter in each column were not significantly different $(\mathrm{P}=0.01)$.

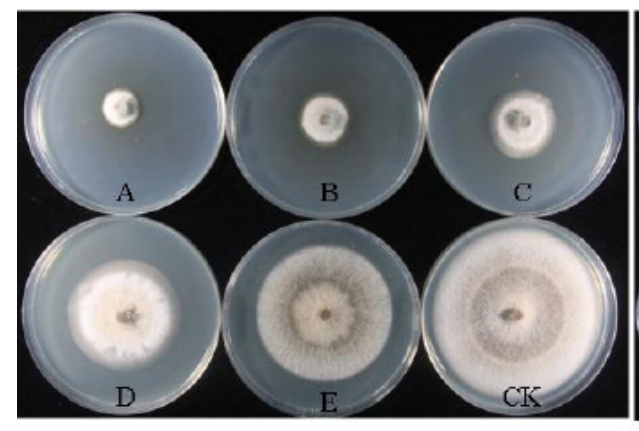

KM12

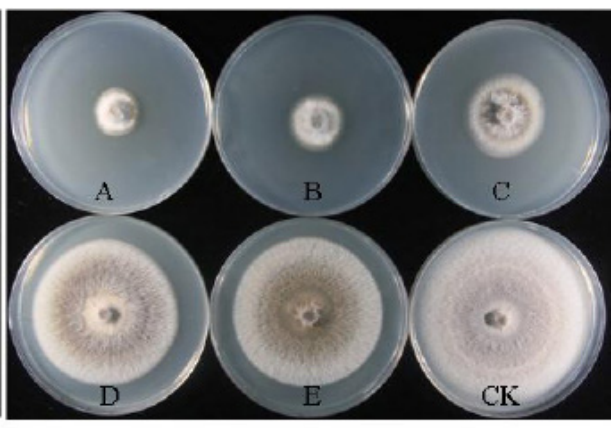

KM16

Figure 1. In vitro effect of isoprothiolane at 6 concentrations on the mycelial growth of blast, 10 DAI. A, B, C, D, $\mathrm{E}$, and $\mathrm{CK}$ are $20,15,10,5,1$, and $0 \mu \mathrm{g} / \mathrm{mL}$, respectively.

Table 3. Effect of varying concentrations of isoprothiolane on mycelial growth of blast isolates carrying specific AvrPik alleles in vitro at 10 days after inoculation.

\begin{tabular}{|c|c|c|c|c|c|}
\hline \multirow[t]{2}{*}{ Isolate/mutant } & \multicolumn{5}{|c|}{ Percent inhibition at different concentrations of isoprothiolane } \\
\hline & $1 \mu \mathrm{g} / \mathrm{mL}$ & $5 \mu \mathrm{g} / \mathrm{mL}$ & $10 \mu \mathrm{g} / \mathrm{mL}$ & $15 \mu \mathrm{g} / \mathrm{mL}$ & $20 \mu \mathrm{g} / \mathrm{mL}$ \\
\hline CHL724 & $11.80^{\mathrm{A}}$ & $29.89^{\mathrm{A}}$ & $59.38^{\mathrm{A}}$ & $68.91^{\mathrm{AB}}$ & $77.97^{\mathrm{B}}$ \\
\hline CHL346 & $11.92^{\mathrm{A}}$ & $35.07^{\mathrm{A}}$ & $61.78^{\mathrm{A}}$ & $77.77^{\mathrm{A}}$ & $85.63^{\mathrm{A}}$ \\
\hline KM1 & $14.94^{\mathrm{A}}$ & $30.27^{\mathrm{A}}$ & $58.57^{\mathrm{A}}$ & $70.42^{\mathrm{B}}$ & $80.44^{\mathrm{AB}}$ \\
\hline KM2 & $15.27^{\mathrm{A}}$ & $31.46^{\mathrm{A}}$ & $60.62^{\mathrm{A}}$ & $72.95^{\mathrm{AB}}$ & $79.36^{\mathrm{AB}}$ \\
\hline KM4 & $11.79^{\mathrm{A}}$ & $27.87^{\mathrm{A}}$ & $57.26^{\mathrm{A}}$ & $72.64^{\mathrm{AB}}$ & $79.46^{\mathrm{AB}}$ \\
\hline KM6 & $16.15^{\mathrm{A}}$ & $33.74^{\mathrm{A}}$ & $59.99^{\mathrm{A}}$ & $73.32^{\mathrm{AB}}$ & $78.04^{\mathrm{B}}$ \\
\hline KM8 & $14.48^{\mathrm{A}}$ & $29.64^{\mathrm{A}}$ & $56.05^{\mathrm{A}}$ & $72.02^{\mathrm{AB}}$ & $80.12^{\mathrm{AB}}$ \\
\hline KM12 & $11.49^{\mathrm{A}}$ & $27.51^{\mathrm{A}}$ & $58.74^{\mathrm{A}}$ & $70.50^{\mathrm{B}}$ & $81.37^{\mathrm{AB}}$ \\
\hline KM14 & $11.96^{\mathrm{A}}$ & $32.22^{\mathrm{A}}$ & $57.49^{\mathrm{A}}$ & $71.29^{\mathrm{AB}}$ & $77.34^{\mathrm{B}}$ \\
\hline KM16 & $11.24^{\mathrm{A}}$ & $33.37^{\mathrm{A}}$ & $59.74^{\mathrm{A}}$ & $71.15^{\mathrm{AB}}$ & $78.35^{\mathrm{B}}$ \\
\hline
\end{tabular}

Means with the same letter in each column were not significantly different $(\mathrm{P}=0.01)$. 


\section{Comparison of virulence fitness costs of $\mathrm{AvrPik}$ alleles isolates to isoprothiolane}

To determine whether there was a correlation between the in vitro susceptibility of AvrPik allele isolates and virulence, $\mathrm{EC}_{50}$ and $\mathrm{EC}_{75}$ were calculated for each mutation isolate and each wild-type isolate. $\mathrm{EC}_{50}$ and $\mathrm{EC}_{75}$ values for inhibition of the isolates are shown in Table 4. The differing virulence isolates KM1 (A/A/A/A) and KM6 (V/V/A/A) exhibited relatively lower $\mathrm{EC}_{50}$ values than the wild-type isolate CHL724, whereas $\mathrm{KM} 4(\mathrm{~A} / \mathrm{A} / \mathrm{A} / \mathrm{A})$ and KM12 (V/V/A/A) showed higher values than the wild-type isolate CHL724 at 6 DAI, respectively. These results suggest that different virulence isolates exhibited nearly the same $\mathrm{EC}_{50}$. The remaining isolates carrying different pathotypes, $\mathrm{V} / \mathrm{A} / \mathrm{A} / \mathrm{A}, \mathrm{V} / \mathrm{V} / \mathrm{V} / \mathrm{V}$, and $\mathrm{V} / \mathrm{V} / \mathrm{A} / \mathrm{V}$, showed a similar $\mathrm{EC}_{50}$ value to the wild-type isolate CHL724. Moreover, the $\mathrm{EC}_{50}$ value increased with longer treatment times and showed slight to moderate changes in 10 DAI. Specifically, the KM4 (A/A/A/A), KM8 (V/V/A/V), KM12 (V/V/A/A), KM14 (V/V/V/V), and $\mathrm{KM} 16(\mathrm{~V} / \mathrm{V} / \mathrm{V} / \mathrm{V})$ showed similar $\mathrm{EC}_{50}$ values to the wild-type isolate CHL724. The remaining isolates $\mathrm{KM} 1, \mathrm{KM} 2$, and KM6 showed significantly lower values compared with the wildtype isolate CHL724.

\begin{tabular}{|c|c|c|c|c|c|}
\hline \multirow[t]{2}{*}{ Isolate/mutant } & \multirow{2}{*}{$\frac{\text { Pathotype }}{P i k p / k / k m / k h}$} & \multicolumn{2}{|c|}{6 days } & \multicolumn{2}{|c|}{10 days } \\
\hline & & $\mathrm{EC}_{50}(\mu \mathrm{g} / \mathrm{mL})$ & $\mathrm{EC}_{75}(\mu \mathrm{g} / \mathrm{mL})$ & $\mathrm{EC}_{50}(\mu \mathrm{g} / \mathrm{mL})$ & $\mathrm{EC}_{75}(\mu \mathrm{g} / \mathrm{mL})$ \\
\hline CHL724 & $\mathrm{V} / \mathrm{V} / \mathrm{V} / \mathrm{V}$ & $5.61^{\mathrm{AB}}$ & $16.13^{\mathrm{AB}}$ & $7.40^{\mathrm{AB}}$ & $20.02^{\mathrm{A}}$ \\
\hline CHL346 & $\mathrm{A} / \mathrm{A} / \mathrm{A} / \mathrm{A}$ & $4.89^{\mathrm{B}}$ & $12.19^{\mathrm{B}}$ & $6.04^{\mathrm{B}}$ & $14.27^{\mathrm{B}}$ \\
\hline KM1 & $\mathrm{A} / \mathrm{A} / \mathrm{A} / \mathrm{A}$ & $4.89^{\mathrm{B}}$ & $15.40^{\mathrm{AB}}$ & $6.89^{\mathrm{AB}}$ & $19.66^{\mathrm{A}}$ \\
\hline KM2 & $\mathrm{V} / \mathrm{A} / \mathrm{A} / \mathrm{A}$ & $5.46^{\mathrm{AB}}$ & $16.49^{\mathrm{AB}}$ & $6.59^{\mathrm{AB}}$ & $18.86^{\mathrm{A}}$ \\
\hline KM4 & $\mathrm{A} / \mathrm{A} / \mathrm{A} / \mathrm{A}$ & $5.98^{\mathrm{A}}$ & $16.47^{\mathrm{AB}}$ & $7.36^{\mathrm{AB}}$ & $19.29^{\mathrm{A}}$ \\
\hline KM6 & $\mathrm{V} / \mathrm{V} / \mathrm{A} / \mathrm{A}$ & $5.26^{\mathrm{AB}}$ & $15.10^{\mathrm{AB}}$ & $6.44^{\mathrm{AB}}$ & $18.94^{\mathrm{A}}$ \\
\hline KM8 & $\mathrm{V} / \mathrm{V} / \mathrm{A} / \mathrm{V}$ & $5.31^{\mathrm{AB}}$ & $16.07^{\mathrm{AB}}$ & $7.02^{\mathrm{AB}}$ & $19.80^{\mathrm{A}}$ \\
\hline KM12 & $\mathrm{V} / \mathrm{V} / \mathrm{A} / \mathrm{A}$ & $6.06^{\mathrm{A}}$ & $16.26^{\mathrm{AB}}$ & $7.43^{\mathrm{A}}$ & $19.40^{\mathrm{A}}$ \\
\hline KM14 & $\mathrm{V} / \mathrm{V} / \mathrm{V} / \mathrm{V}$ & $5.63^{\mathrm{AB}}$ & $16.92^{\mathrm{A}}$ & $7.25^{\mathrm{AB}}$ & $19.93^{\mathrm{A}}$ \\
\hline KM16 & $\mathrm{V} / \mathrm{V} / \mathrm{V} / \mathrm{V}$ & $5.65^{\mathrm{AB}}$ & $16.73^{\mathrm{A}}$ & $7.07^{\mathrm{AB}}$ & $18.61^{\mathrm{A}}$ \\
\hline
\end{tabular}

Means with the same letter in each column were not significantly different $(\mathrm{P}=0.01)$.

For the $\mathrm{EC}_{75}$ value the most virulent pathotype V/V/V/V isolates KM14 and KM16 exhibited higher $\mathrm{EC}_{75}$ values compared to the wild-type isolate CHL724 at 6 DAI. The remaining mutation isolates, including the KM1 (A/A/A/A), showed similar $\mathrm{EC}_{75}$ values compared to the wild-type isolate CHL724. However, in all mutation isolates, the $\mathrm{EC}_{75}$ value was similar to CHL724 at 10 DAI. Overall, these results suggest that there are no fitness costs associated with the sensitivity of blast isolates carrying specific AvrPik alleles to different pathotypes with respect to the $\mathrm{EC}_{50}$ and $\mathrm{EC}_{75}$ values at 6 and $10 \mathrm{DAI}$.

\section{DISCUSSION}

The inhibitory effect of isoprothiolane against many plant and animal pathogenic fungi has been reported in several studies. Isoprothiolane is effective for treating fat necrosis in Japanese Black cattle (Oka et al., 1988) and experimentally induced fatty liver in Holstein cattle (Nagasawa et al., 1989) and rats (Imaizumi et al., 1981). Isoprothiolane increased proliferation of mammary epithelial cells in a dose-dependent manner at concentrations of 0.05-5 $\mu \mathrm{M}$ when cultured either with or without serum-supplemented medium. In contrast, isoprothiolane 
(0.0005-5 $\mu \mathrm{M})$ significantly inhibited the production of IL-1 and IL- 6 by mammary epithelial cells (Okada et al., 1999). Although isoprothiolane has been widely used to control rice blast in China since the 1980s (Yuan et al., 2005; Qi et al., 2013), this is the first study examining blast isolates carrying specific AvrPik alleles. The results showed that isoprothiolane inhibits mycelial growth of blast isolates carrying specific AvrPik alleles in vitro at all 5 concentrations used, particularly at high concentrations.

The fitness of an organism is defined as its combined ability to survive and reproduce (Pringle and Taylor, 2002). For example, in fungi, smaller spores can be dispersed more effectively and therefore be more fit than larger spores, even if larger spores have greater germination rates; moreover, stabilizing selection can optimize spore size (Meerts, 1999). The fitness of an individual genotype can also be measured by choosing a single spore and using the asexually derived progeny of that spore to measure a specific aspect of fitness, such as mycelial growth rate (Antonovics and Alexander, 1989). A number of recent studies have investigated the fitness costs of virulence at the Avr locus. The L. maculans-Brassica napus pathosystem confirmed a fitness cost of virulence at the AvrLm4 locus in L. maculans on hosts without the corresponding $R$ gene $R \operatorname{lm} 4$ (Huang et al., 2006). Studies suggest that there is no fitness cost for virulence at the AvrLm2 and AvrLm 3 loci because the avirulent alleles AvrLm2 or $A v r L m 3$ are very rare or completely absent in European populations (Rouxel et al., 2003; Balesdent et al., 2006; Stachowiak et al., 2006). In contrast, there may be a fitness cost at the AvrLm1 and AvrLm4 loci because AvrLm1 and AvrLm4 are still present in L. maculans populations, although cultivars containing $R$ genes $R \operatorname{lm} 1$ and $R \operatorname{lm} 4$ have been used commercially for over 10 years. However, in this study, no relationship between AvrPik allele virulence and $\mathrm{EC}_{50}$ or $\mathrm{EC}_{75}$ values was observed for all AvrPik alleles isolates. No fitness costs were associated with the virulence trait in the AvrPik loci. Similar results have been reported by Ziogas and Kalamarakis (2001), who found that a fungicide-resistant Botrytis cinerea pathogen was as virulent as the wild-type strain, demonstrating that chemical resistance may not impose a fitness cost. Although no fitness costs were observed in the AvrPik loci in this present study, fitness costs cannot be ruled out in other aspects, as various aspects of individual fitness during the immature and adult stages may be affected by biotic and abiotic factors. Therefore, the fitness of AvrPik alleles can be accurately compared by testing for a variety of fitness parameters, including the radial growth of mycelia on petri dishes, spore germination, mean length of germ tubes, and pathogenicity.

\section{ACKNOWLEDGMENTS}

Research supported by the National Natural Science Foundation (\#30870102; \#U1131003), the National "973" Project (\#2011CB1007001), and the National Transgenic Plant Project (\#2011ZX08001-002). We thank John Hu for help with revising the manuscript.

\section{REFERENCES}

Antonovics J and Alexander HM (1989). The Concept of Fitness in Plant-Fungal Pathogen Systems. In: Plant Disease Epidemiology: Genetics, Resistance, and Management. Vol. 2. (Leonard KJ and Fry WE, eds.). McGraw-Hill, New York, 185-214.

Balesdent MH, Louvard K, Pinochet X and Rouxel T (2006). A large-scale survey of races of Leptosphaeria maculans occurring on oilseed rape in France. Eur. J. Plant Pathol. 114: 53-65.

Ballini E, Morel JB, Droc G, Price A, et al. (2008). A genome-wide meta-analysis of rice blast resistance genes and 
quantitative trait loci provides new insights into partial and complete resistance. Mol. Plant Microbe Interact. 21: 859-868.

Dai Y, Jia Y, Correll J, Wang X, et al. (2010). Diversification and evolution of the avirulence gene AVR-Pital in field isolates of Magnaporthe oryzae. Fungal Genet. Biol. 47: 973-980.

Farman ML and Leong SA (1998). Chromosome walking to the AVRI-CO39 avirulence gene of Magnaporthe grisea: discrepancy between the physical and genetic maps. Genetics 150: 1049-1058.

Fudal I, Bohnert HU, Tharreau D and Lebrun MH (2005). Transposition of MINE, a composite retrotransposon, in the avirulence gene ACE1 of the rice blast fungus Magnaporthe grisea. Fungal Genet. Biol. 42: 761-772.

Huang YJ, Li ZQ, Evans N, Rouxel T, et al. (2006). Fitness cost associated with loss of the AvrLm4 avirulence function in Leptosphaeria maculans (phoma stem canker of oilseed rape). Eur. J. Plant Pathol. 114: 77-89.

Huang YJ, Balesdent MH, Li ZQ, Evans N, et al. (2010). Fitness cost of virulence differs between the AvrLm 1 and AvrLm4 loci in Leptosphaeria maculans (phoma stem canker of oilseed rape). Eur. J. Plant Pathol. 126: 279-291.

Imaizumi Y, Sugimoto T and Kasai T (1981). Effect of diisopropyl 1,3-dithiol-2-ylidenemalonate (NKK-105) on fatty liver induced by carbon tetrachloride. Jpn J. Pharmacol. 31: 15-21.

Jia Y, McAdams SA, Bryan GT, Hershey HP, et al. (2000). Direct interaction of resistance gene and avirulence gene products confers rice blast resistance. EMBO J. 19: 4004-4014.

Jia Y, Wang Z, Fjellstrom RG, Moldenhauer KA, et al. (2004). Rice Pi-ta gene confers resistance to the major pathotypes of the rice blast fungus in the United States. Phytopathology 94: 296-301.

Jones JD and Dangl JL (2006). The plant immune system. Nature 444: 323-329.

Kang S, Sweigard JA and Valent B (1995). The PWL host specificity gene family in the blast fungus Magnaporthe grisea. Mol. Plant-Microbe Interact. 8: 939-948.

Leach JE, Vera Cruz CM, Bai J and Leung H (2001). Pathogen fitness penalty as a predictor of durability of disease resistance genes. Annu. Rev. Phytopathol. 39: 187-224.

Lee FN, Cartwright RD, Jia Y and Correll JC (2005). A Preliminary Characterization of the Rice Blast Fungus in the Banks Variety. In: Wells Rice Research Studies 2004 (Norman RJ, Meullenet JF and Moldenhauer KAK, eds.). University of Arkansas Agricultural Experiment Station Research Series, Fayetteville, 103-110.

Li W, Wang B, Wu J, Lu G, et al. (2009). The Magnaporthe oryzae avirulence gene AvrPiz- $t$ encodes a predicted secreted protein that triggers the immunity in rice mediated by the blast resistance gene Piz-t. Mol. Plant Microbe Interact. 22: $411-420$

Liu J, Wang X, Mitchell T, Hu Y, et al. (2010). Recent progress and understanding of the molecular mechanisms of the rice-Magnaporthe oryzae interaction. Mol. Plant Pathol. 11: 419-427.

Ma JH, Wang L, Feng SJ, Lin F, et al. (2006). Identification and fine mapping of AvrPi15, a novel avirulence gene of Magnaporthe grisea. Theor. Appl. Genet. 113: 875-883.

Meerts P (1999). The evolution of spore size in Agarics: do big mushrooms have big spores? J. Evol. Biol. 12: 161-165.

Moldenhauer KA, Lee FN, Norman RJ and Helms RJ (1990). Registration of 'Katy' rice. Crop Sci. 30: 747-748.

Nagasawa S, Yamanaka H, Motoi Y, Ishikawa T, et al. (1989). Effect of isoprothiolane on hepatic lesions of heifer caused by carbon tetrachloride. Nihon Juigaku. Zasshi 51: 284-293.

Oka A, Yamasaki T, Shibatani M, Suzuki T, et al. (1988). Efficacy of isoprothiolane for the treatment of fat necrosis in cattle. Br. Vet. J. 144: 507-514.

Okada H, Miyake Y, Ohtsuka H, Kiku Y, et al. (1999). Effects of isoprothiolane on cell growth of cultured bovine mammary epithelial cells. J. Vet. Med. Sci. 61: 553-556.

Orbach MJ, Farrall L, Sweigard JA, Chumley FG, et al. (2000). A telomeric avirulence gene determines efficacy for the rice blast resistance gene Pi-ta. Plant Cell 12: 2019-2032.

Padmavathi G, Ram T, Satyanarayana K and Mishra B (2005). Identification of blast (Magnaporthe grisea) resistance genes in rice. Cur. Sci. 88: 628-630.

Pringle A and Taylor J (2002). The fitness of filamentous fungi. Trends Microbiol. 10: 474-481.

Qi ZQ, Ju XJ, Liu WW and Ji MS (2013). Sensitivity detection of Pyricularia gresea to isoprothiolane in Liaoning province (In Chinese). Acta Phytopathol. Sin. 43: 173-178.

Rouxel T, Penaud A, Pinochet X and Brun H (2003). A 10-year survey of populations of Leptosphaeria maculans in France indicates a rapid adaptation towards the Rlm1 resistance gene of oilseed rape. Eur. J. Plant Pathol. 109: 871-881.

Séré Y, Onasanya A, Afolabi A and Mignouna HD (2007). Genetic diversity of the blast fungus, Magnaporthe grisea (Hebert) Barr, in Burkina Faso. Afri. J. Biotechnol. 6: 2568-2577.

Stachowiak A, Olechnowicz J, Jedryczka M and Rouxel T (2006). Frequency of avirulence alleles in field populations of Leptosphaeria maculans in Europe. Eur. J. Plant Pathol. 114: 67-75.

Sweigard JA, Carroll AM, Kang S, Farrall L, et al. (1995). Identification, cloning, and characterization of PWL2, a gene 
for host species specificity in the rice blast fungus. Plant Cell 7: 1221-1233.

Takahashi M, Ashizawa T, Hirayae K, Moriwaki J, et al. (2010). One of two major paralogs of AVR-Pita1 is functional in Japanese rice blast isolates. Phytopathology 100: 612-618.

Talbot NJ (2003). On the trail of a cereal killer: Exploring the biology of Magnaporthe grisea. Annu. Rev. Microbiol. 57: 177-202.

Uesugi Y (2001). Pesticide outlook, fungal choline biosynthesis-a target for controlling rice blast. 1: 26-27.

Vera Cruz CM, Bai J, Oña I, Leung H, et al. (2000). Predicting durability of a disease resistance gene based on an assessment of the fitness loss and epidemiological consequences of avirulence gene mutation. Proc. Natl. Acad. Sci. U. S. A. 97: 13500-13505.

Wang L, Xu X, Lin F and Pan Q (2009). Characterization of rice blast resistance genes in the Pik cluster and fine mapping of the Pik-p locus. Phytopathology 99: 900-905.

$\mathrm{Wu} \mathrm{W}$ (2012). Genetic diversity and evolution of the AvrPik alleles in the rice blast pathogen populations. PhD thesis, South China Agricultural University, Guangzhou.

Yoshida K, Saitoh H, Fujisawa S, Kanzaki H, et al. (2009). Association genetics reveals three novel avirulence genes from the rice blast fungal pathogen Magnaporthe oryzae. Plant Cell 21: 1573-1591.

Yuan J, Yang XH, He YH and Jin X (2005). Test on resistance of Magnapothe grisea to isoprothiolane in Guizhou province in Chinese. Acta Phytopathol. Sin. 35: 71-73.

Zhai C, Lin F, Dong Z, He X, et al. (2011). The isolation and characterization of Pik, a rice blast resistance gene which emerged after rice domestication. New Phytol. 189: 321-334.

Zhou E, Jia Y, Singh P, Correll JC, et al. (2007). Instability of the Magnaporthe oryzae avirulence gene AVR-Pita alters virulence. Fungal Genet. Biol. 44: 1024-1034.

Ziogas BN and Kalamarakis AE (2001). Phenylpyrrole fungicides: mitotic instability in Aspergillus nidulans and resistance in Botrytis cinerea. J. Phytopathol. 149: 301-308. 